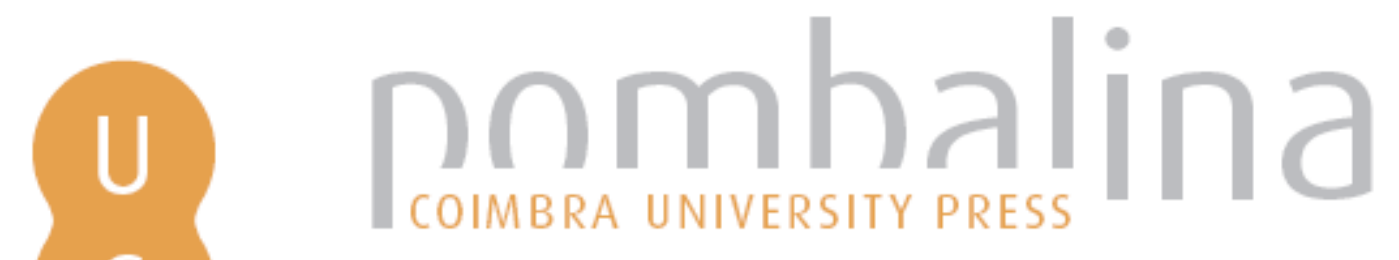

\title{
A observação do Universo: a utopia de atingir o inatingível
}

\author{
Autor(es): $\quad$ Fernandes, João
}

Publicado por: Imprensa da Universidade de Coimbra

URL

persistente: URI:http://hdl.handle.net/10316.2/32074

DOI: $\quad$ DOI:http://dx.doi.org/10.14195/978-989-26-0499-2_23

Accessed : $\quad$ 26-Apr-2023 15:44:32

A navegação consulta e descarregamento dos títulos inseridos nas Bibliotecas Digitais UC Digitalis, UC Pombalina e UC Impactum, pressupõem a aceitação plena e sem reservas dos Termos e Condições de Uso destas Bibliotecas Digitais, disponíveis em https://digitalis.uc.pt/pt-pt/termos.

Conforme exposto nos referidos Termos e Condições de Uso, o descarregamento de títulos de acesso restrito requer uma licença válida de autorização devendo o utilizador aceder ao(s) documento(s) a partir de um endereço de IP da instituição detentora da supramencionada licença.

Ao utilizador é apenas permitido o descarregamento para uso pessoal, pelo que o emprego do(s) título(s) descarregado(s) para outro fim, designadamente comercial, carece de autorização do respetivo autor ou editor da obra.

Na medida em que todas as obras da UC Digitalis se encontram protegidas pelo Código do Direito de Autor e Direitos Conexos e demais legislação aplicável, toda a cópia, parcial ou total, deste documento, nos casos em que é legalmente admitida, deverá conter ou fazer-se acompanhar por este aviso.

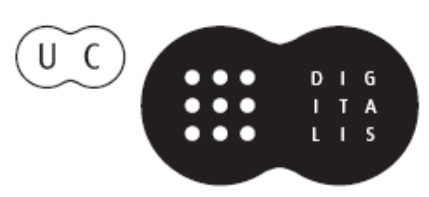


Maria de Fátima Silva

Coordenação

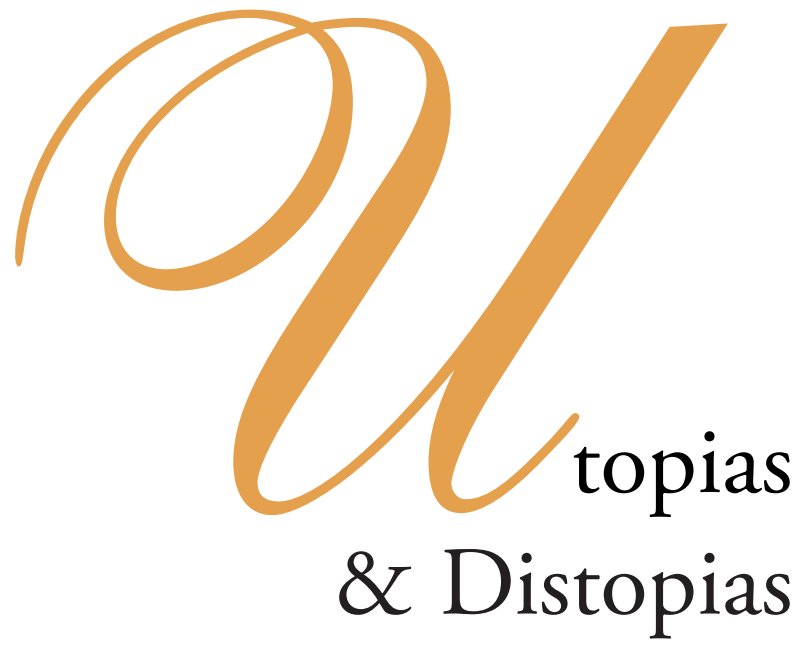




\section{COORDENAÇÃO EDITORIAL \\ Imprensa da Universidade de Coimbra \\ Email: imprensauc@ci.uc.pt \\ URL: http://www.uc.pt/imprensa_uc}

\section{CONCEPÇÃO GRÁFICA}

António Barros

Pré-IMPRESSÃo

Tipografia Lousanense, Lda.

EXECUÇÃO GRÁFICA

Tipografia Lousanense, Lda.

ISBN

978-989-8074-74-4

DEPósito LEGAL

289002/09

OBRA PUBLICADA COM O APOIO DE:

Centro de Estudos Clássicos e Humanísticos

Faculdade de Letras da Universidade de Coimbra

FCT Fundação para a Ciência e a Tecnologia

MINISTÉRIO DA CIÊNCIA, TECNOLOGIA E ENSINO SUPERIOR Portugal 
Maria de Fátima Silva

Coordenação
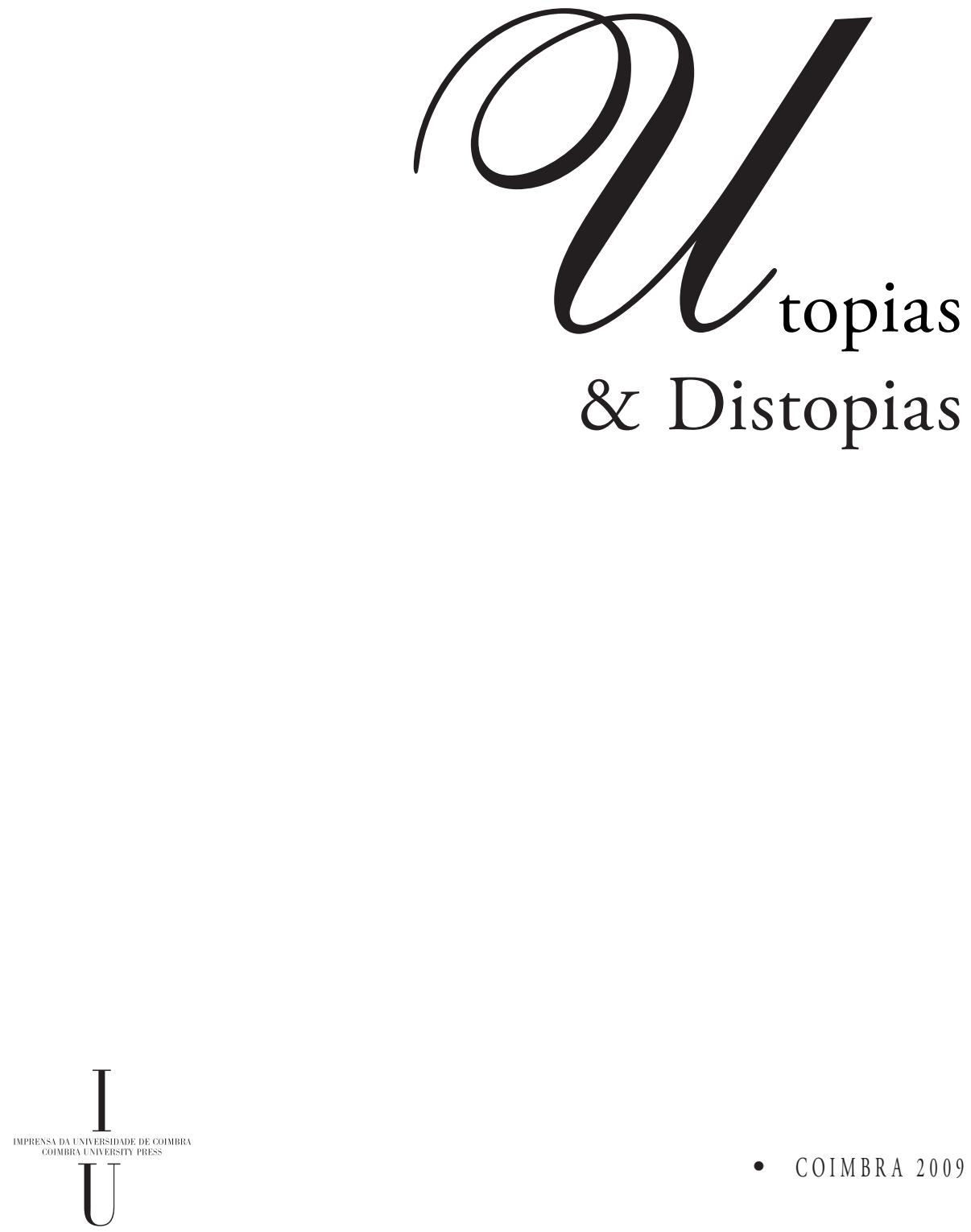

- colmbra 2009 

João Fernandes

\author{
A OBSERVAÇÃo DO UNIVERSO: \\ A UTOPIA DE ATINGIR O INATINGÍVEL
}

\title{
1. Introdução:
}

Astronomia é a ciência que estuda os astros. Esta definição simples encerra em si toda a complexidade de alguém (ciência ou cientista) que se aventura no conhecimento dos astros. De todos os astros? Sim, de todos sem excepção!

Comecemos pelo princípio, ou seja, comecemos por nós próprios enquanto observadores. Numa noite de céu estrelado, longe da poluição luminosa dos grandes centros urbanos, é difícil não fixarmos o olhar na abóbada celeste que nos circunda, e envolve, dando a aparente sensação de nos encontramos no centro de um enorme planetário, ocupando um lugar privilegiado para a observação astronómica. "Observação astronómica”, sim! É que esta não necessita necessariamente de instrumentos ou de aparelhos de ampliação da imagem (telescópios). A humanidade observa o Universo com esses aparelhos há apenas 400 anos. Até ao início do século XVII todo o estudo astronómico passava pela observação a olho nu com a mesma técnica que permite a cada um de nós deleitar os sentidos na tal noite de céu estrelado. E o que pode afinal cada um de nós ver? Confesso que gostaríamos de não responder a esta pergunta, convidando cada um a fazer a experiência por si e dar tempo para ouvir as respostas. Por outro lado, convencemo-nos que alinhavando aqui uma resposta à pergunta poderia motivar alguém mais renitente para, na tal noite do céu estrelado, levantar os olhos ao firmamento e usufruir...

Em todo o caso, não será difícil imaginar que o começo da Astronomia perde-se nos confins dos tempos. Há evidências de que observaçôes astronómicas estão presentes na disposição das pirâmides egípcias, construídas em 3000 a.C., ou no Stonehenge, erigido pelos habitantes das ilhas britânicas há mais de 4000 anos. No entanto, não será difícil admitir que a observação do firmamento é tão antiga quanto o próprio Homem.

$\mathrm{O}$ interesse da Humanidade no aperfeiçoamento do conhecimento sobre o Universo reparte-se por diversas razôes. Antes de mais por razão de ordem prática. Alguns fenómenos celestes são periódicos e por isso fornecem cronómetros naturais de importância extrema para a evolução e organização da vida humana. A navegação marítima, do período das Descobertas, teve também como consequência o desenvolvimento da arte de observar e medir os céus. Mas há também razóes de interesse puro no avanço dos conhecimentos. São inúmeros os exemplos que cruzam a História da civilização. 
Assim, da observação astronómica resulta a tentativa da compreensão do Universo através de leis tão generalizáveis quanto possível, isto é, o astrónomo espera que ao estudar, por exemplo, o Sol esteja a contribuir para o estudo de todas as estrelas com propriedades semelhantes à do Astro Rei. Poderemos argumentar que este procedimento é geral na Ciência e em todas as suas áreas. Será assim! Mas na Astronomia toma uma dimensão especial, tendo em conta as escalas espaciais e temporais que envolvem os objectos astronómicos. Por um lado, a maior parte dos objectos estudados pelo astrónomo estão muito longe ${ }^{1}$ e não é possível intervenção directa, ou seja, "tocar" ou fazer experiências em laboratório (excluindo os raros exemplos da análise de rochas lunares ou marcianas e de asteróides caídos na Terra). Por outro lado, o tempo de evolução dos astros é demasiado elevado ${ }^{2}$ para que possamos assistir, em directo, ao desenrolar do filme do Universo. Assim, não deixa de ser extraordinário que Homem ambicione o estudo dos astros com escalas espaciais e temporais tão distintas. É essa a Utopia!

Porém, a radiação electromagnética (vulgo luz) que nos chega dos astros é a nossa ligação a eles. Admitindo as mesmas propriedades fundamentais da radiação emitida por qualquer astro, então o progresso da Astronomia faz-se pela comparaçáo/confronto entre os conceitos teóricos e as observaçôes.

Hoje em dia, a ideia do estudo dos astros está profundamente ancorada na questão instrumental, a saber, nos meios de observação como os grandes telescópios instalados à superfície terrestre ou os telescópios-satélites colocados em órbita ou em sondas espaciais. Mas, durante muitos séculos foi o olho nu que trouxe à Humanidade resultados que foram permitindo o conhecimento do Universo. E de alguma forma vencer esta Utopia que se coloca ao Homem.

Hoje o Homem tem à sua disposição uma panóplia de extraordinários meios de observaçóes que lhe permite "aterrar" em Marte ou descobrir planetas extra-solares. Mas não foi sempre assim. Por outro lado a Humanidade não teve que esperar pelo século XX para começar a desvendar esses segredos cósmicos. Muito antes o fez, e por vezes com artefactos que fariam sorrir cientista de hoje. Mas que importantes resultados se obtiveram então... É sobre alguns deles que nos iremos deter, especialmente, neste texto.

\section{O saber Astronómico pré-telescópio: os primórdios da conquista da utopia}

Usando uma metodologia particularmente simples, Eratóstenes (276-195 a.C.) consegue estimar um valor do raio da Terra. O método estava baseado na observação simultânea do Sol em dois locais à superfície da Terra, suficientemente afastados: Assuão (ex-Syene) e Alexandria (a quase $800 \mathrm{~km}$ de distância de Assuáo). No caso de Assuão, no solstício de verão, os raios solares iluminavam o fundo de um poço fruto do facto do Sol culminar no zénite do lugar. Por outro lado, em Alexandria, à mesma hora, uma barra vertical projectava sombra (Fig. 1 e 2)

\footnotetext{
${ }^{1}$ A estrela mais próxima da Terra, depois do Sol, está a mais de 40000 mil milhôes de quilómetros!

${ }^{2} \mathrm{O}$ Sol que nasceu há 4.6 mil milhôes de anos, terá outro tanto de vida!
} 

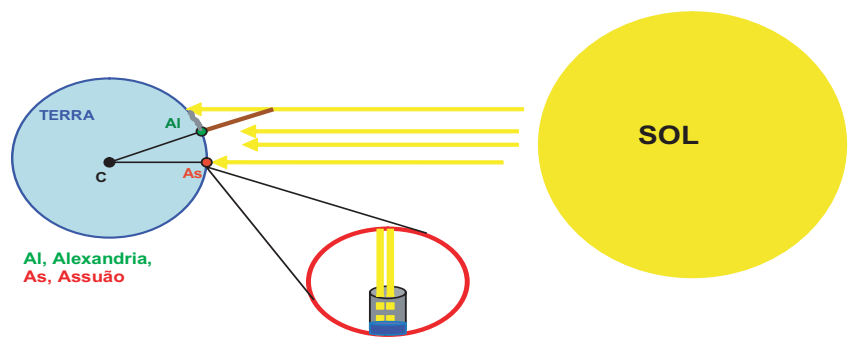

Figura 1. Determinação do raio da Terra por Eratóstenes: observaçóes durante o solstício de verão.

Uma simples construção geométrica ...

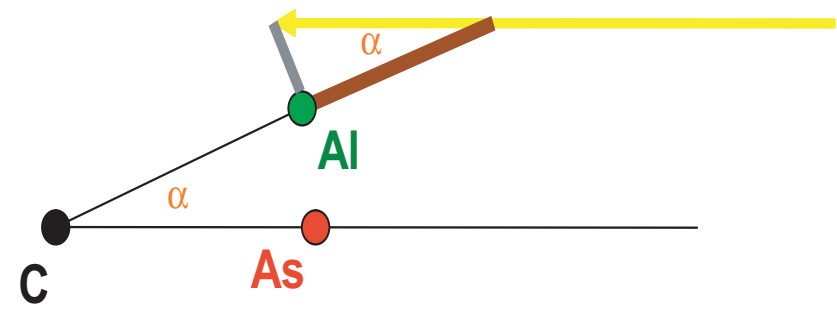

Figura 2. Determinação do raio da Terra por Eratóstenes.

... permite concluir que

$$
\begin{aligned}
& \tan \alpha=\frac{\text { sombra }}{\text { altura }} \Rightarrow \alpha \approx 7.2^{\circ} \\
& \text { Usando d_AsAl } \approx 800 \mathrm{~km}, \\
& \mathrm{R}=\frac{800 \times 360}{7.2 \times 2 \pi}=6366 \mathrm{~km}
\end{aligned}
$$

O valor espanta pela coincidência com o valor actual de $6378 \mathrm{~km}$ (raio equatorial). Esta foi, seguramente, a primeira determinação fiável da medição do raio da Terra. Posteriormente, Posidonius de Rodes (135-51 a.C.) usou um método semelhante, baseando-se em observaçóes da estrela Canopus, para redeterminar o raio da Terra.

Os métodos geométricos permitiram outras determinaçóes. Aristarco de Samos (310 - 230 a.C.), mais famoso pela sua permatura proposta heliocêntrica, fez uma primeira estimativa da distância relativa Terra-Sol (DS) e Terra-Lua (DL) usando observaçóes da Lua em quadratura (Fig. 3) 


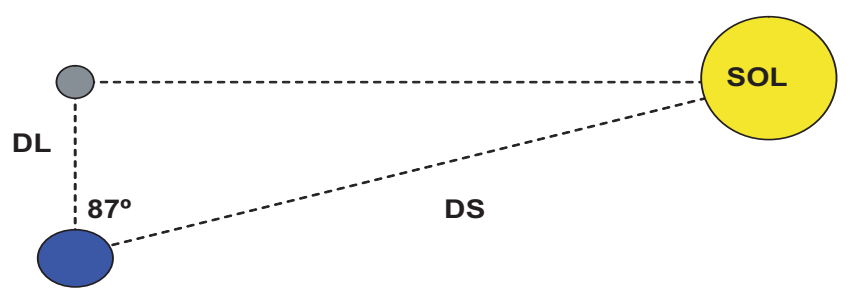

Figura 3. Determinação das distâncias relativas Terra-Sol (DS) e Terra-Lua (DL).

O valor obtido foi da ordem de DS/DL - 20, algo menos impressionante do que o caso anterior quando comparado com o valor actual ( -400$)$, embora plenamente justificável tendo em conta os meios e distâncias envolvidas. Em todo o caso "some Greek astronomers were more fascinated with finding out how to answer a question, than with answering it" (Hoskin 1999, p.34).

Por outro lado, e num registo mais "astrofísico", encontramos hipóteses de que foi Anaxágoras (500- 428 a.C.) o primeiro a observar uma mancha solar em 467 a. C. (Bicknell, 1964). Sendo ou não Anaxágoras, é certo que o primeiro registo de uma mancha solar foi feito muito antes da invenção do telescópio. A figura 4 mostra um desenho de uma mancha feito em 1129 por um monge inglês de nome John of Worcester.

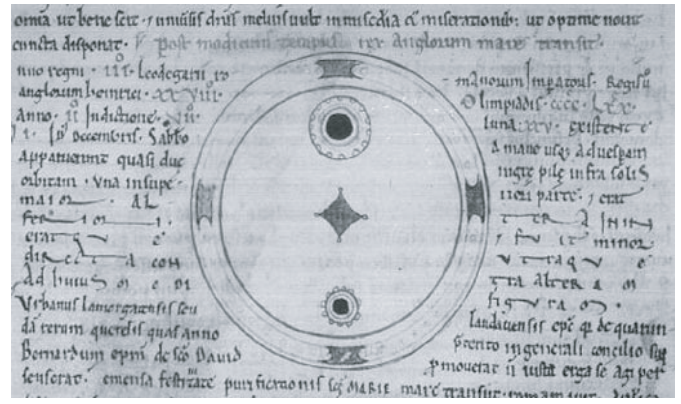

Figura 4. Desenho da mancha solar da autoria de John of Worcester no séc. XII.

(Fonte da imagem: http://en.wikipedia.org/wiki/Image:ChroniclesofJohnofWorcester.jpg).

Apesar da, já referida, motivação essencialmente intelectual e filosófica na compreensáo do Universo por parte do sábios gregos, não é menos certa a preocupação em reproduzir a realidade. Este facto está bem presente, por exemplo, nas correcçóes e melhoramentos introduzidos no modelo geocêntrico. É o caso da proposta de Hipparcus de Niceia (190-120 a.C.), que sabia que as estaçóes do ano tinham amplitudes temporais diferentes: Primavera-Verão $=94,5$ dias, Verão-Outuno $=92,5$ dias, etc. Assim, o movimento do Sol em torno da Terra estaria mais em consonância com as observaçóes se a Terra ocupasse, não o centro da órbita, mas um ponto afastado e descentrado (Fig. 5). 


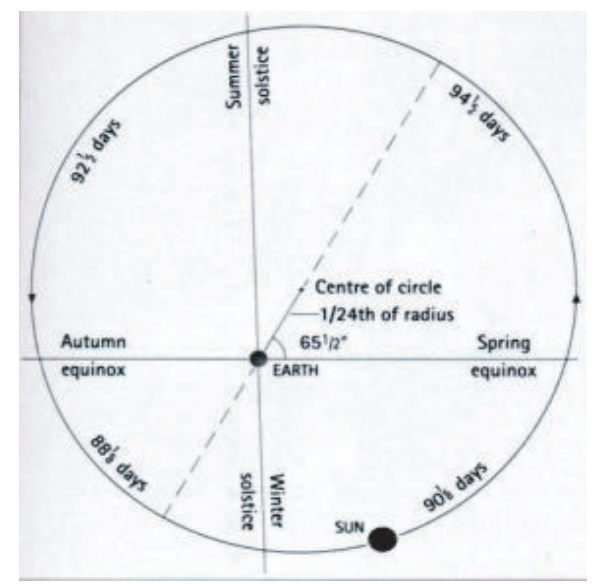

Figura 5. Hipparcus de Niceia e o modelo que contempla estações do ano de duração variável (Fonte da imagem: Hoskin 1999, p. 38)

Por outro lado, com objectivo de explicar o movimento retrógrados dos planetas, nascem os epicíclos.

Seja a figura 6. Quando observado, em diferentes instantes, da Terra (T), a trajectória (aparente) de um planeta (P) ocupa na esfera celeste as posiçóes "A". Repara-se na figura 6, que a posição aparente do planeta na esfera celeste A4 aparece entre as posiçóes A1 e A3 e contudo o instante 4 é posterior a estes dois. É como se o movimento do planeta (visto da Terra) invertesse o sentido.

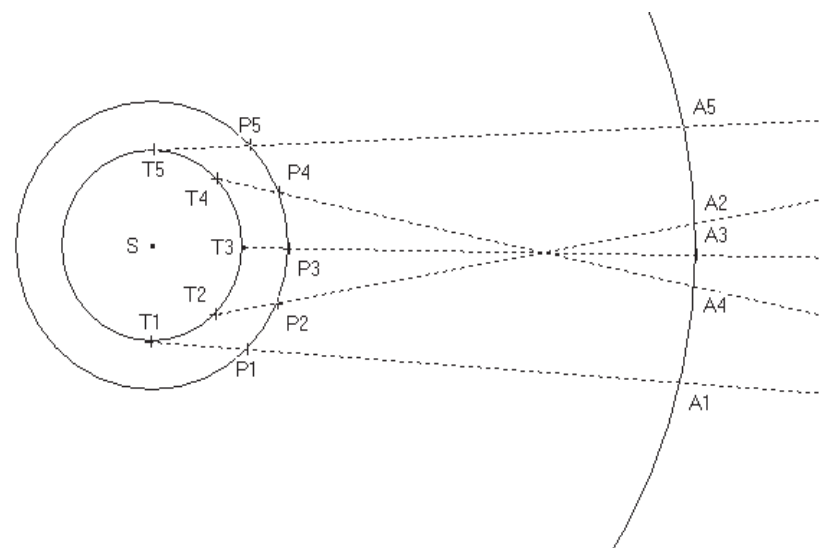

Figura 6. O Movimento retrógrado dos planetas.

(Fonte da imagem: http://upload/wikipedia.org/wikipedia/commons/f/fc/Retrogadation.png) 
Sendo que o modelo geocêntrico impunha um movimento planetário sempre no mesmo sentido, havia que fazer algo. Para salvaguardar o modelo desta observação foram adicionados os epicíclos, sobre os quais os planetas se movem. O centro do epicíclo, descreve assim, uma órbita - o deferente - em torno da Terra (Fig. 7).

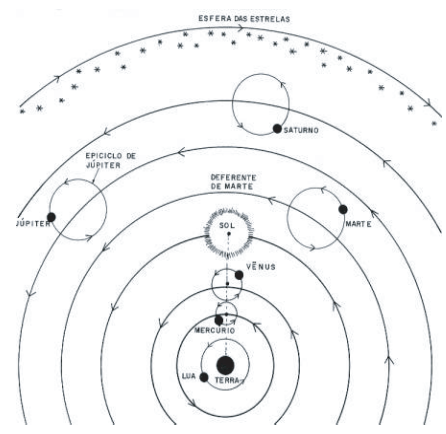

Figura 7. O modelo geocêntrico com epicíclos e deferentes.

(Fonte da imagem: desconhecida)

O modelo geocêntrico foi a base do ensino e compreensão do Universo até meados dos século XVI. Aí inicia-se um século de ouro onde personagens como Copérnico, Brahe, Kepler e Galileu levam a ciência e a Astronomia a um patamar nunca antes atingido. Pela sua importância, abordaremos esta época com mais algum detalhe.

\section{Os séculos XVI e XVII: as épocas de ouro !}

Com Nicolau Copérnico (1473-1543), o modelo heliocêntrico toma novo impulso: o Sol no centro e os planetas (Mercúrio, Vénus, Terra, Marte, Júpiter e Saturno) em órbita deste (Fig. 8).

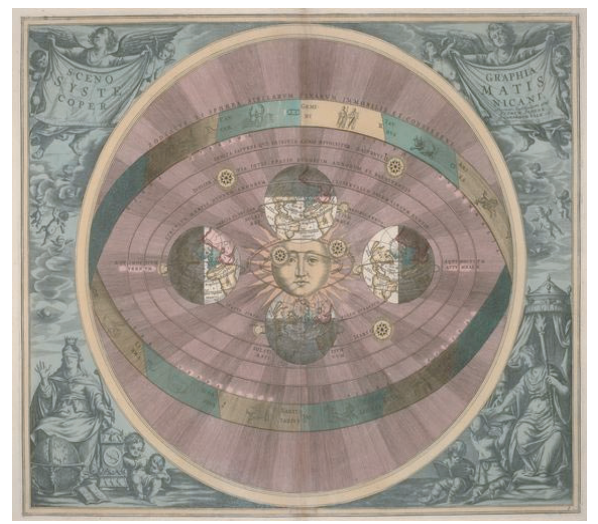

Figura 8. O modelo heliocêntrico de Copérnico (Andreas Cellarius, Harmonia Macrocosmica, 1708).

(Fonte da imagem: http://wikipedia.org/wiki/imagem:heliocentric.jpg) 
Apresentado pelo próprio autor como um artefacto matemático mais simples para a determinaçáo dos movimentos planetários, este modelo vai ocupar papel cimeiro nas discussóes dos anos seguintes.

Johanes Kepler (1571-1630) foi, provavelmente, o último grande astrónomo a extrair do Universo a olho nu relevantes resultados. E quão relevantes são as suas três leis!

Kepler era um heliocêntrista convicto e via em Tycho Brahe (1546-1601), e nas suas observaçóes, uma oportunidade para confrontar as asserçóes teóricas sobre o movimento dos planetas. Kepler e Brahe náo terão convivido durante muito tempo, um ano talvez. Porém, parece certo que o seu relacionamento não foi fácil. Afastando-nos, neste contexto, das recentes teorias (mais ou menos) conspirativas que atribuem a Kepler responsabilidade moral e material (!) da morte de Brahe (Gilder and Gilder, 2005), o facto é que Tycho reconhecia no jovem Johanes valor como matemático e como astrónomo. Consta até, que na sua agonia final, Tycho teria doado as observaçôes que fizera de Marte a Kepler para que "A minha vida não tenha sido em vão".

Com essas observaçóes, Kepler trabalhou afincadamente nos anos seguintes e em 1609 publicou uma obra chamada "Astronomia nova" onde é proposto que as órbitas dos planetas são elipses e o Sol ocupa um dos focos. Esta proposta ficou conhecida como a primeira lei de Kepler.

Kepler chega a esta conclusão depois de ter analisado detalhadamente as posiçóes de Marte relativamente ao Sol e ter constatado que a órbita desenhada pelo planeta se afastava de uma circunferência. A diferença, entre a solução circular e as observaçôes, encontrada por Kepler, era da ordem de 8 minutos de arco, ou seja, $0.13^{\circ}$. Kepler poderia muito bem ter interpretado esta diferença como um erro de observação. Contudo, Kepler sabia a qualidade das observaçóes do grande observador. Brahe dispunha, na altura, do equivalente hoje em dia aos melhores telescópios do Mundo: um enorme quadrante mural (Fig. 9).

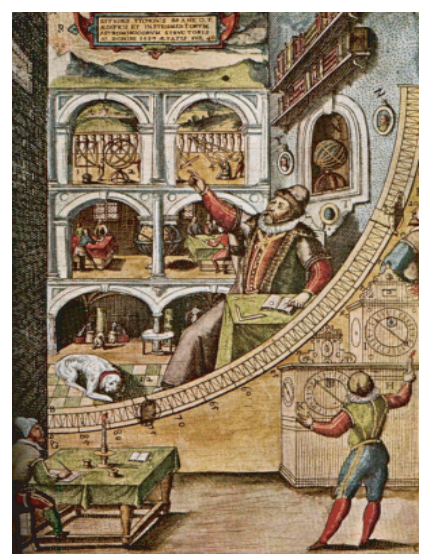

Figura 9. Tycho Brahe e o quadrante mural no Observatório de Uraniborgue (Dinamarca) (Fonte: http://www.ccvalg.pt/astronomia/historia/tycho_brahe.htm) 
Este instrumento permitia a Tycho ter uma precisão nas observaçôes da poucos minutos de arco. Uma curiosidade relaciona os métodos (rigorosos) de observação de Tycho com Portugal: de facto, Tycho Brahe, terá usado o conceito do nónio da autoria Pedro Nunes. Numa carta que Tycho escreve ao matemático Cristóvão Rothmann em 1587 pode ler-se "Mas, logo que em seguida, comecei a tomar rigorosamente a altura dos astros com a ajuda de quadrantes e me apercebi pela experiência, que a divisão comum, levada o mais longe possível, não era suficiente nos pequenos instrumentos, recorri ao subtil processo que Nunes apresenta na terceira preposiçáo do seu De Crepusculis, e o tornei mais exacto, aumentando o número de subdivisóes e calculando tábuas pelas quais se poderia conhecer imediatamente e com precisão a altura de um ponto qualquer. E, como esta invenção de Nunes, assim como a experiência me tinha provado, não satisfazia as suas promessas, eu pergunto-me se o processo, pelo qual se chega, por meio de pontos transversais, a dividir uma recta em partes muito pequenas, náo poderia aplicar-se também às linhas curvas."7

Assim, Kepler, confiante na qualidade dos dados que tinha na máo, abandona a hipótese de órbita circular para Marte. Este despojar de um conceito - o da circulariedade das órbitas - é particularmente notável em Kepler, já que ele acreditava que os planetas desenhavam, justamente, órbitas circulares em torno do Sol. Anos antes, numa obra de juventude, Kepler tinha postulado um intrincado modelo do sistema solar em que os espaços interplanetários eram quantificáveis pelos cinco poliedros regulares (Fig.10).

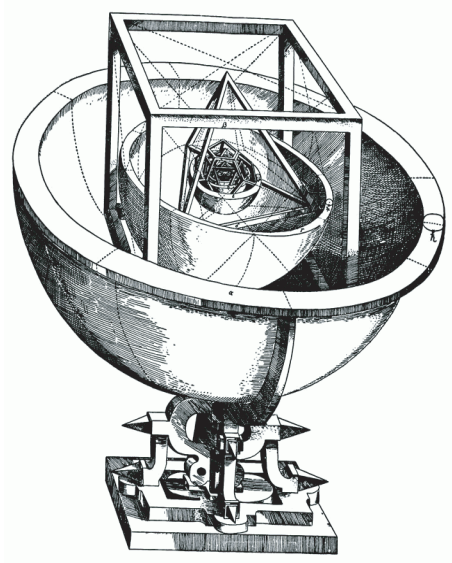

Figura 10. O "Misterium Cosmographycum" e os poliedros regulares.

A obra em causa chama-se "Misterium Cosmographycum" e foi publicada em 1596. "Eu pretendo provar que Deus, criando o Universo dando regras à disposição

\footnotetext{
${ }^{7}$ Citado em “Centro Virtual Camões, Ciência em Portugal” (http://www.istituto-camoes.pt/cvc/ciencia/e20b.html)
} 
dos Céus, teve em vista os cinco poliedros regulares da geometria, célebres desde Pitágoras e Platão, fixando, tendo em conta as suas dimensôes, o número, as suas proporçóes e a relação entre os respectivos movimentos", escreve Kepler na obra.

Regressando à "Astronomia nova”, Kepler mostra ainda, aquela que viria a ser perpetuada como, a segunda lei de Kepler: um vector imaginário que liga o Sol ao planeta varre áreas iguais em intervalos de tempos iguais. Esta lei tem uma consequência imediata: a velocidade escalar do planeta aumenta quando este se aproxima do Sol, obtendo o valor máximo no ponto da órbita mais próximo do Sol, o periélio.

A terceira lei de Kepler, veio a ser mostrada em 1619 numa nova obra de Kepler de nome "Hormonicis Mundi", onde é exposto um tratado fazendo corresponder os movimentos planetários a uma celeste composição musical. Nesta terceira lei é referido que o quociente do quadrado do período orbital pelo cubo do semi-eixo maior da órbita planetária é uma constante.

Como é claro, as leis de Kepler são de natureza empírica e (apesar de Kepler ter já consciência da importância do Sol como "motor" dos movimentos planetários) estas só vieram a ser compreendidas à luz da mecânica Newtoniana. No quadro da teoria Teoria da Gravitação Universal de Isacc Newton (1643-1727) a força mútua de atracção gravitacional entre o Sol e o planeta (Fig. 11)...

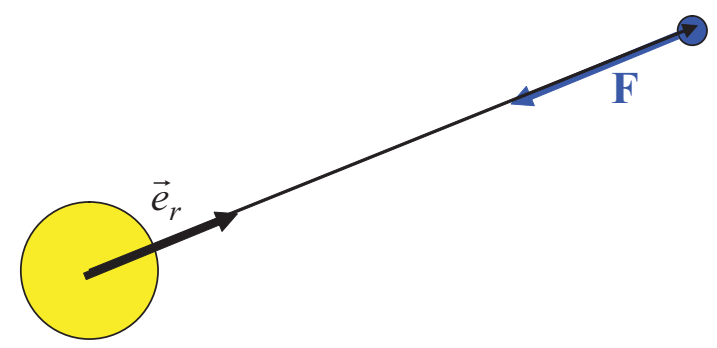

Figura 11. Força atractiva Sol-planeta.

... é descrita pela Lei da Gravitação Universal:

$$
F=-\frac{G M m}{r^{2}} \vec{e}_{r}
$$

onde $G$ é a constante de gravitação universal, $M$ a massa do Sol e $m$ a massa do planeta. Assumindo a segunda lei de Newton, podemos escrever:

$$
\vec{F}=m \vec{a}=m \frac{d^{2} \vec{r}}{d t^{2}}=-\frac{G M m}{r^{2}} \vec{e}_{r}
$$

O que conduz a uma equação diferencial cuja integração permite demonstrar que, 


$$
r(t)=\frac{p}{1+e \cos \theta(t)}
$$

que é, como se sabe, a equação de uma cónica em coordenadas polares. Este resultado náo só integra a primeira lei de Kepler - órbita elíptica - como a amplia para a possibilidade das órbitas poderem (pelos menos em termos teóricos) ser parábolas ou hipérboles.

Por outro lado, ainda no quadro da Lei da Gravitaçáo Universal, demonstra-se a terceira lei de Kepler na forma:

$$
\frac{P^{2}}{a^{3}}=\frac{4 \pi^{2}}{G M}
$$

dando significado físico à constante encontrada por Kepler.

É um facto que a Astronomia de Kepler é baseada na observação a olho nu. Por outro lado é curiosa a coincidência temporal entre o estabelecimento das leis de Kepler (1609 e 1619) e as primeiras observaçôes com uso do telescópio por Galileu em 1609-1610. De uma certa forma Galileu abre a porta da astronomia moderna com o uso do telescópio enquanto Kepler "fecha" a porta da astronomia a olho nu. Mas fechaa com chave de ouro!

Por volta de 1608, o astrónomo italiano Galileu Galileu (1564-1642) toma conhecimento de notícias vindas da Holanda sobre um óculo que permite uma visão ampliada de objectos distantes. Galileu empreende a construção de um instrumento similar e com ele regista observaçóes astronómicas nos primeiros meses de 1610 . Galileu, tendo seguramente consciência da importância das suas descobertas, publica rapidamente (a 12 de Março desse ano!) o seu "Sidereus Nuncius” e dá a conhecer ao Mundo que existe um universo muito mais vasto, para lá do que olhos humanos podem apreender (Fig. 12).

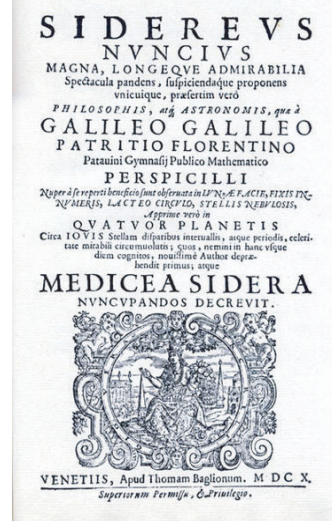

Figura 12. Frontispício do "Sidereus Nuncius" (1610) 
Com um telescópio dotado de uma lente que não aumentava mais de uma dezena de vezes, Galileo descobre que Júpiter tem satélites tal como a Terra tem a Lua e que esta é, afinal, um corpo cravejado de crateras. Mostra ainda que há mais estrelas no céu do que as visíveis a olho nu.

Após a publicação do livro, Galileu continua as suas observações: Saturno (em Abril de 1610) e as manchas do Sol em 1613. Porém, é ainda no final de 1610 que Galileu faz aquela que é provavelmente a sua observação astronómica de maior impacto: as fases de Vénus. Tal como a Lua, Galileu observa que Vénus tem fases incluindo a "Vénus-Cheia" (Fig. 13).

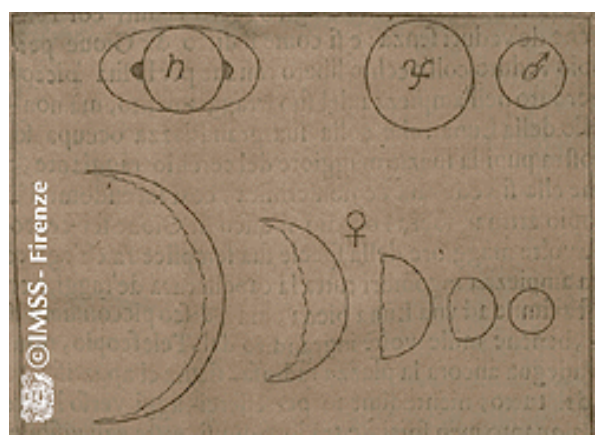

Figura 13. Registo das observaçôes das fases de Vénus. Nesta imagem vêem-se ainda outras observaçóes entre as quais se destaca Saturno, no canto superior esquerdo

(Fonte da imagem: Istituto e Museo di Storia della Scienza- Firenze, Italia).

Porém tal como pode ser constatado na figura 14, o modelo geocêntrico não prevê a existência de uma fase cheia (ou quase) para Vénus.

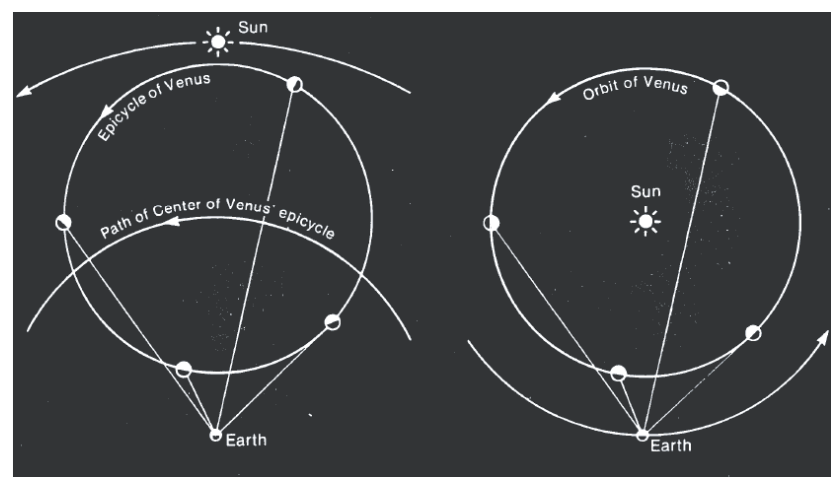

Figura 14. As fases de Vénus vistas pelos dois modelos: geocêntrico e heliocêntrico (Fonte da imagem: Gingerich 2003) 
Assim Galileu destrona, com este fundamental conjunto de observações, o modelo geocêntrico. Para mais detalhes consultar Palmieri (2001).

Porém, dar argumentos observacionais que invalidem a hipótese geocêntrica é uma coisa. Outra coisa, é a validação do modelo heliocêntrico. Ou seja, a derrota de uma modelo náo conduz, per si, à vitória de outro. Os modelos são ... modelos e, por isso, pode sempre arranjar-se tantos modelos que reproduzam as observaçóes quando o engenho e a criatividade humana o permitirem.

E, curiosamente, era disso que se tratava. É que os modelos geocêntrico e de heliocêntrico não eram os únicos modelos discutidos na época. Tycho Brahe, que não acreditava no movimento da Terra (baseado no facto de náo se conseguir observar a paralaxe estelar) propôs um modelo alternativo que conjugava as ideias geocêntricas e heliocêntricas: a Terra encontra-se no centro; a Lua e o Sol têm movimentos em torno dela; mas os restantes planetas orbitam em torno do Sol (Fig. 15).

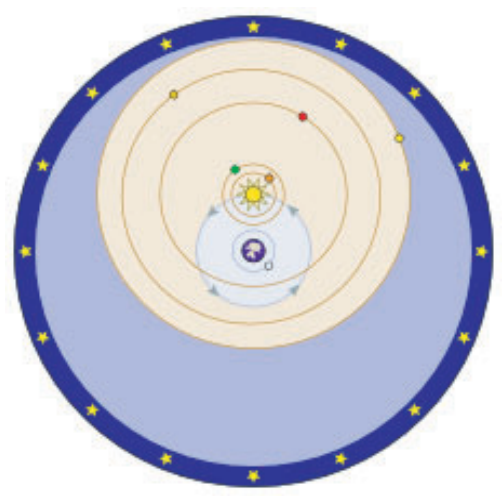

Figura 15. O modelo de Tycho Brahe.

Fonte: http://en.wikipedia.org/wiki/Image:Tychonian_system.svg

O curioso é que o modelo de Tycho também permite uma explicação das fases de Vénus, em particular a "Vénus-Cheia". Assim, observado da Terra, as fases de Vénus são igualmente reproduzidas pelos modelos de Copérnico - heliocêntrico - e pelo de Tycho Brahe.

Esta constatação de que os dois modelos reproduziam as observaçôes astronómicas então conhecidas, deu origem a um interessantíssimo debate em que os astrónomos jesuítas estiveram particularmente envolvidos.

A figura 16 apresenta o frontispício da obra de Giovanni Battista Riccioli, de 1651, onde se sugere um pender da balança para Tycho em detrimento de Copérnico. De igual forma, na "Aula da Esfera” proferida por Giovanni Paolo Lembo, no colégio de Santo Antão em Lisboa, entre 1615 e 1617, são rejeitados os modelos heliocêntrico e geocêntrico dando preferência ao modelo de Tycho Brahe ou a suas variações (Leitão, 2008). 
Frequentemente os textos pedagógico-didácticos secundarizam a discussão dos três sistemas, centrando-se na dicotomia copérnico-ptolomeu. De facto o processo e a condenação de Galileu em 1633, lamentável acontecimento (para Ciência, para Galileu e para a própria Igreja), acabou por deslocar o centro de gravidade de uma problemática que (para lá de motivaçôes teológicas) tem, na sua génese, a discussão de argumentos científicos.

Em todo o caso, o que importa aqui valorizar é a introdução do telescópio. O Homem compreende então que a construção de telescópios cada vez maiores podem "trazer" para perto o mais longínquo.

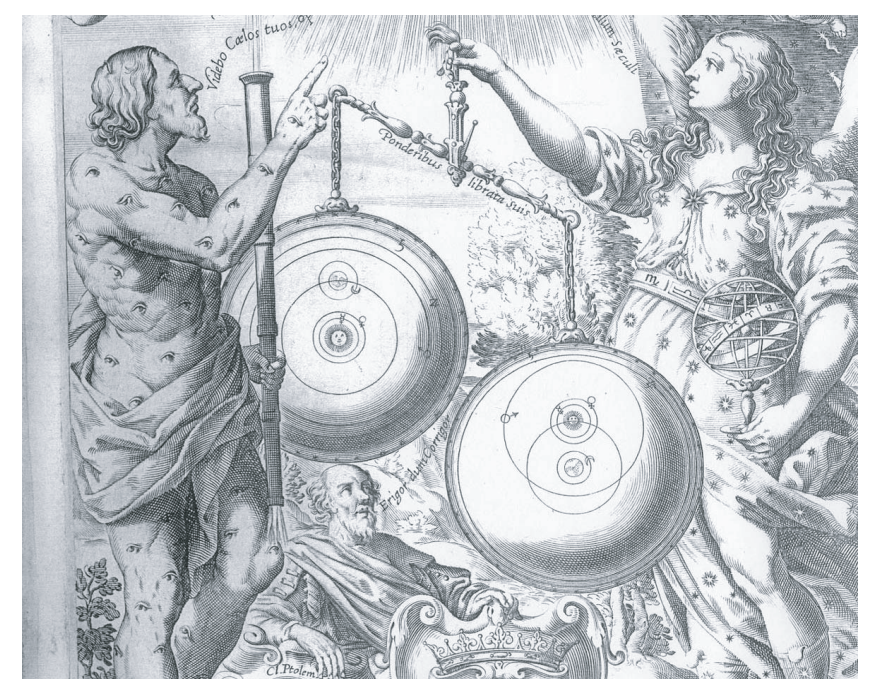

figura 16. Frontispício de "Almagestum novum" de Giovanni Battista Riccioli (1651)

\section{Consideraçóes finais.}

No séc. XIX, duas novas realidades vêm dar um desenvolvimento maior ao estudo da Astronomia. Em 1880 William Hershel póe em evidência a radiação infravermelha. Sucedem-se, em finais do século, a descoberta das ondas de rádio por Heinrich Hertz e dos raios X por Wilhelm Roentgen. Temos assim um outro universo para além do visível. Além deste facto, e também por causa dele, os astrónomos rapidamente compreendem que não seria suficiente a simples observação, mas haveria necessidade de guardar e medir a luz vinda dos astros. Instrumentos como o espectroscópio ou o fotómetro cumprem então esta missão e dão um novo avanço à Astronomia em particular e à Ciência em geral. Assim, já não interessa só conhecer as posiçôes e trajectórias dos astros, como até então, mas também as suas propriedades intrínsecas: composição química, temperatura, energia irradiada, etc. As preocupaçóes do desenvolvimento experimental vão estar sempre na vanguarda da Astronomia e permitem que se chegue ao início do séc. XXI com telescópios de $10 \mathrm{~m}$ de diâmetro 
colocados à superfície da Terra, telescópios espaciais, que nos revelam os confins (e o início) do Universo e sondas que visitam outros planetas do nosso Sistema Solar. Enfim, vencer a utopia de conhecer aqueles objectos cósmicos, cuja grande maioria, o Homem não poderá visitar directamente nos próximos séculos.

\section{Bibliografia:}

Joshua Gilder and Anne-Lee Gilder. "Heavenly Intrigue: Johannes Kepler, Tycho Brahe, and the Murder Behind One of History's Greatest Scientific Discoveries". Ed. Random House CA(2005)

Gingerich, Owen. "Truth in Science: Proof, Persuasion, and the Galileo Affair", Perspectives on Science and Christian Faith, Volume 55, Number 2, p. 80 (2003)

Hoskin, Michael. "The Cambridge Concise History of Astronomy” Ed. Cambridge UP (1999)

Leitão, Henrique. "Sphaera Mundi: A Ciência na Aula da Esfera". Biblioteca Nacional (2008)

Palmieri, Paolo, "Galileo and the discovery of the phases of Venus" Journal for the History of Astronomy (ISSN 0021-8286), Vol. 32, Part 2, No. 107, pp. 109 - 129 (2001) 



\section{Série}

\section{Documentos}

Imprensa da Universidade de Coimbra

Coimbra University Press

2009

- $\mathrm{U}$

C • 